\title{
A DINÂMICA DAS FRONTEIRAS E A MIGRAÇÃO HAITIANA CONTEMPORÂNEA
}

Alex Dias de Jesus ${ }^{1}$ Jones Dari Goettert ${ }^{2}$

Resumo: A antiga e intensa migração de haitianos pelo mundo ajudou a transformar o Haiti em uma sociedade transnacional, profundamente conectada com diversos destinos através das redes sociais entre migrantes e não migrantes. A partir de 2010, além da continuidade da migração para tradicionais destinos, os haitianos incorporaram países da América do Sul ao seu espaço migratório. Entretanto, as estratégias de mobilidade e atravessamento de fronteiras estão diretamente vinculadas às políticas migratórias adotadas pelos países de destino e de trânsito desses migrantes, contribuindo para a reconfiguração desses movimentos. Diante disso, o presente estudo objetivou analisar a relação entre a migração haitiana contemporânea e as políticas migratórias de alguns dos seus destinos. Para este fim, a metodologia utilizada baseou-se em revisão bibliográfica e documental publicada nos países que atualmente configuram-se como destinos dessa intensa mobilidade.

Palavras-chave: Fronteiras. Migração haitiana. Políticas migratórias.

\section{THE DYNAMICS OF BORDERS AND CONTEMPORARY HAITIAN MIGRATION}

Abstract: The ancient and intense migration of Haitians around the world has helped transform Haiti into a transnational society, deeply connected to various destinations through social networks between migrants and non-migrants. As of 2010, in addition to continuing migration to traditional destinations, Haitians have incorporated South American countries into their migratory space. However, the mobility and border crossing strategies are directly linked to the migration policies adopted by the countries of destination and transit of these migrants, contributing to the reconfiguration of these movements. Therefore, the present study aimed to analyze the relationship between contemporary Haitian migration and the migratory politicals of some of its destinations. For this, the methodology used was based on a bibliographical and documentary revision published in the countries that currently constitute themselves as destinations of this intense mobility.

Keywords: Borders. Haitian migration. Migration politicals.

\section{LA DINÁMICA DE LAS FRONTERAS Y LA MIGRACIÓN HAITIANA CONTEMPORÁNEA}

Resumen: La antigua e intensa migración de haitianos por el mundo ayudó a transformar a Haití en una sociedad transnacional, profundamente conectada con diversos destinos a través de las redes sociales entre migrantes y no migrantes. A partir de 2010, además de la continuidad de la migración a destinos tradicionales, los

\footnotetext{
1 Instituto Federal do Piauí, Departamento de Ensino, São Raimundo Nonato, Brasil, alexdias@ifpi.edu.br, https://orcid.org/0000-0002-4464-935X

2 Universidade Federal da Grande Dourados, Faculdade de Ciências Humanas, Dourados, Brasil, jonesdari@ufgd.edu.br, https://orcid.org/0000-0002-8571-279X
} 
haitianos incorporaron países de América del Sur a su espacio migratorio. Sin embargo, las estrategias de movilidad y atravesamiento de fronteras están directamente vinculadas a las políticas migratorias adoptadas por los países de destino y de tránsito de esos migrantes, contribuyendo a la reconfiguración de esos movimientos. Ante eso, el presente estudio tuvo como objetivo analizar la relación entre la migración haitiana contemporánea y las políticas migratorias de algunos de sus destinos. Para este fin, la metodología utilizada se basó en una revisión bibliográfica y documental publicada en los países que actualmente se configuran como destinos de esa intensa movilidad.

Palabras clave: Fronteras. Migración haitiana. Politicas migratorias.

\section{Introdução}

O objetivo deste artigo é refletir sobre a dinâmica das fronteiras internacionais no que diz respeito às políticas migratórias contemporâneas e seus desdobramentos na migração haitiana. Para isso, a metodologia consistiu em análise bibliográfica e documental de materiais que, de alguma maneira, relacionam-se com os fluxos migratórios de haitianos pelo mundo nas primeiras décadas do século XXI.

A migração internacional tem marcado profundamente o Haiti e os haitianos dentro e fora do país, fazendo essa pequena nação caribenha ser atravessada por processos transnacionais cada vez mais intensos. Há pelo menos um século, os haitianos têm se deslocado por variados destinos do mundo, ampliando seu espaço social para além das fronteiras do Estado nação.

A presença de haitianos no exterior é tão significativa que a ideia de um "novo espaço haitiano", desde a década de 1980, passou a incorporar os variados destinos dessa migração como parte do Haiti. Na academia, Glick-Schiller (2011) afirma que, entre os estudiosos do transnacionalismo, acredita-se que geógrafo George Anglade foi o primeiro a utilizar o termo "décimo departamento 3" para se referir aos haitianos no exterior. Os trabalhos dele demonstraram que a sociedade haitiana está muito além das fronteiras do Haiti.

No Estado, o reconhecimento efetivo dessa questão se deu em 1994, durante o governo de Jean Bertrand Aristide, com a criação do Ministério dos Haitianos Residentes no Exterior (MHAVE), reformulado em 2011, no governo de René Preval. Sob a responsabilidade dele está a maior parte dos serviços relacionados à emigração, dentre eles a organização anual da Jornada Internacional da Diáspora (HANDERSON, 2015).

\footnotetext{
${ }^{3} \mathrm{Na}$ época existiam nove departamentos no Haiti como forma de regionalização do Estado. Os haitianos no exterior eram considerados o décimo. Atualmente existem dez departamentos, sendo os migrantes fora do país considerados o décimo primeiro.
} 
Enquanto fenômeno de grande dimensão e continuidade no tempo, a mobilidade haitiana assume formas variadas desde o início do século $X X$. $O$ processo migratório está intimamente ligado à história do Haiti. Postos em movimento, milhões de haitianos expandiram o espaço desse país para muito além de suas fronteiras demarcadas, produzindo um espaço transnacional a partir de variados vínculos. Atualmente, mais de 25 países contêm grupos de haitianos superiores a 500 pessoas (ALFONSO, 2012). Mais do que os números, as relações entre os diferentes destinos e o Haiti, materializadas pelos sujeitos em mobilidade, lançam luz na compreensão desse processo.

Iniciadas no início do século XX através da contratação de trabalhadores temporários para as empresas agropecuárias norte-americanas em Cuba e na República Dominicana, a grande migração internacional dos haitianos se expandiu para diversos países do mundo. De acordo com Handerson (2015), entre 4 e 5 milhões de haitianos estão fora do Haiti, principalmente nos Estados Unidos, República Dominicana, Canadá e França. Contudo, nos últimos anos, novos destinos passaram a fazer parte desse processo, a exemplo do Brasil e Chile.

Ao longo de mais de um século, os haitianos desenvolveram variadas estratégias de mobilidade em diversos países, recriando comunidades haitianas fora do Haiti e ampliando o espaço transnacional. Atualmente, a grande mobilidade dos haitianos pelo continente americano está profundamente relacionada com as políticas migratórias adotadas por alguns países, e por isso acreditamos que a análise delas pode contribuir no entendimento da questão.

\section{A dinâmica das fronteiras: mecanismos de controle frente à migração}

A ampliação das desigualdades, desastres ambientais, conflitos e violências variadas seguem sendo fortes causas impulsionadoras das migrações internacionais. De acordo com a Organização Internacional das Migrações, em 2019, existiam aproximadamente 272 milhões de migrantes internacionais, o que correspondia a cerca de $3.5 \%$ da população mundial (OIM, 2019). Com a intensa e às vezes dramática circulação de pessoas, as fronteiras foram recolocadas enquanto espaços privilegiados da gestão do território e da afirmação da soberania nacional, "onde os direitos servem mais a si, enquanto os deveres servem mais aos vizinhos" (OLIVEIRA, 2005). Em resposta à intensificação da circulação de pessoas através das fronteiras nacionais, a xenofobia e a efetivação de políticas restritivas à mobilidade ganharam amplitude no século XXI. 
As políticas de securitização das fronteiras, já presentes enquanto estratégias de combate ao contrabando, estão sendo ressignificadas frente aos fluxos migratórios. Em uma tentativa de associação entre tráfico e migração, discursos e ações que colocam em prática restrições à mobilidade humana têm se proliferado em várias partes do mundo. Entretanto, rotas de fuga ou estratégias de contornamento das barreiras, físicas ou jurídicas, são criadas pelos migrantes em um contínuo atravessamento de fronteiras.

Entretanto, é preciso considerar que a fronteira não serve apenas para diferenciar e separar. Ela é também espaço de conexão, de contato com o outro e de trocas cotidianas. "A fronteira não é uma linha, a fronteira é um dos elementos da comunicação biossocial que assume uma função reguladora" (RAFFESTIN, 2005, p. 15). Para aqueles que vivem em espaços de fronteira internacional, principalmente em conurbações binacionais, o trânsito alternado entre regimes jurídicos e costumes diferentes faz parte do cotidiano e a fronteira se manifesta mais como elemento de contato do que de separação.

Dorfman (2013) propõe considerar a especificidade do viver na fronteira enquanto condição fronteiriça, assumindo que as fronteiras não são estáveis e por isso os comportamentos frente a elas também são mutáveis conforme as circunstâncias.

A condição fronteiriça é entendida como um "saber passar" adquirido pelos habitantes da fronteira, acostumados a acionar as diferenças e semelhanças nacionais, linguísticas, jurídicas, étnicas, econômicas, religiosas que ora representam vantagens, ora cerceamento de trânsito ou direitos (DORFMAN, 2013, p. 10).

Em tempos de informação e comunicação instantâneas, os migrantes têm utilizado cada vez mais ferramentas para acelerar a circulação de informações e desenvolver novas estratégias de atravessamento ou contornamento das barreiras. Embora necessariamente não sejam habitantes da fronteira, desenvolvem um "saber passar" temporário, frequentemente obtendo informações de contatos muito distantes dos espaços fronteiriços. No passado e no presente, migrantes e fronteiras sempre estiveram em permanente associação. Como as formas de migrar mudaram, os regimes fronteiriços também o fizeram.

A perspectiva histórica nos estudos migratórios contribui para o entendimento de que migrantes tiveram papel fundamental no desenvolvimento de diversas sociedades ao redor do mundo. Durante maior parte da história da humanidade não existiram mecanismos que identificassem e caracterizassem o estrangeiro, até 
porque essa categoria está diretamente vinculada à formação dos Estados nacionais, em oposição à categoria de nacional.

O controle das fronteiras surgiu com a formação dos Estados nacionais e o consequente exercício de soberania sobre determinado território. O Estado adquiriu o monopólio da autoridade para restringir e controlar os movimentos através e dentro de suas fronteiras. Com isso, houve a necessidade de identificação e autorização para circular. As fronteiras e o controle fronteiriço identificaram e classificaram os nacionais e os estrangeiros e exerceram controle sobre suas mobilidades. Tal controle objetivava o alistamento militar, cobranças de impostos, proteção e retenção de mão de obra local, contenção e exclusão de indivíduos indesejáveis, segurança, dentre outros (FARIA, 2015).

Segundo Faria (2015), a primeira referência ao termo passaporte encontra-se na virada do primeiro milênio, na Inglaterra, durante o reinado de Guilherme, quando foram construídos cinco portos de entrada e passou-se exigir aprovação para ingresso através da passagem pelos portos, daí o termo passport. Na Europa mercantilista, a consideração de que a mão de obra era equivalente à riqueza, dificultava a emigração e estimulava a imigração, sobretudo de artesãos. Com a Revolução Industrial, embora tenha havido maior liberalização da circulação de bens e capitais, o deslocamento populacional manteve-se objeto de restrições e controles.

A grande migração de europeus para o continente americano, principalmente nos séculos XIX e início do século XX, caracterizou-se, na maioria dos casos, por ausência de restrições e, ao contrário, até por incentivos pelos governos dos países de destino. "Pode-se ponderar que as hoje ex-colônias não têm gozado das mesmas vantagens oferecidas à Europa pelas migrações, em termos de alternativa para a busca de melhores condições de vida ou para o equilíbrio do crescimento populacional" (FARIA, 2015, p. 121).

Nos Estados Unidos, frente à imigração europeia, em destaque para britânicos, irlandeses e alemães, ainda no século XIX começaram as pressões para restringir e até mesmo interromper as migrações internacionais. Implantou-se sistemas de maior diferenciação e restrição, como o controle do número de migrantes por navio e realização de estatísticas sobre migrações. Mais tarde, em 1882, o governo promulgou o Chinese Exclusion Act que suspendeu a imigração chinesa pelo prazo de dez anos (FARIA, 2015). A seletividade do perfil ideal de migrante sustentou e continua sustentando políticas migratórias restritivas em muitos países. 
O Ato de Exclusão dos Chineses e considerado precursor da legislação federal e da atitude norte-americana atual em relação aos imigrantes, que tende a ser pautada por abordagem seletiva dos migrantes $e$ frequentemente baseada em considerações de raça. Ressalte-se que também outros países orientais foram objeto de restrições de imigração da parte dos EUA, como japoneses e filipinos, com base em preocupações forjadas na crença de que esses povos representavam "raças inferiores" (FARIA, 2015, p. 125).

Ainda em 1924, o sistema de cotas por nacionalidade foi estabelecido nos Estados Unidos. A lei de migração de 1965, apesar de garantir a reunificação familiar, também impôs limites e restrições. A Lei de Controle e Reforma da Imigração de 1986 anistiou milhões de imigrantes indocumentados, mas contribuiu para a militarização da fronteira. Entre 1985 e 2002, os gastos com detenção e expulsão de migrantes cresceram 750\% (PIÑEIRO e LANDA, 2018). Esses critérios, embora com mudanças ao longo do tempo, permaneceram nas políticas migratórias estadunidenses com reflexos diretos na migração de latino-americanos e caribenhos.

O muro na fronteira sul com o México é a forma mais visível do controle e restrição à mobilidade. Embora sua seção inicial tenha sido construída em 1962, em San Diego, na Califórnia, com uma extensão de $6,8 \mathrm{Km}$, a militarização não se restringiu às barreiras físicas. A Lei de Reforma da Imigração llegal e de Responsabilidade do Imigrante, de 1996, aumentou o financiamento da Patrulha Fronteiriça e consequentemente da vigilância sobre os atravessamentos na área de limite internacional com o México. Em 2006, a Lei de Muro Seguro autorizou a construção de $1.127 \mathrm{~km}$ adicionais de muro e atualmente ele corresponde a $35 \%$ da fronteira (PIÑEIRO e LANDA, 2018).

As restrições à migração internacional nos Estados Unidos aumentaram após os atentados de 11 de setembro de 2001 e impactaram diretamente nos fluxos de latino-americanos que para lá se dirigem, influenciando na escolha de outros possíveis destinos da migração. Apesar de a vigilância e controle remeterem a décadas anteriores e em ritmo crescente, a construção de um grande muro na fronteira com o México foi um tema de destaque nas eleições presidenciais de 2016. Embora a promessa de Donald Trump ainda não tenha se efetivado, outros atos têm dificultado os planos de milhões de migrantes que estão ou que pretendem entrar naquele país. Trump recorreu ao uso de ações executivas para incrementar reforços militares na fronteira, impor restrições de ingresso para muçulmanos e renovar o uso 
de discricionariedade em processos de deportação, revertendo políticas de Barack Obama (PIÑEIRO e LANDA, 2018).

Além dos Estados Unidos, a intensidade dos fluxos de migrantes e refugiados ao redor do mundo tem colocado as fronteiras internacionais na pauta das discussões em torno da soberania e segurança nacionais. Paradoxalmente, o discurso de um mundo conectado, sem fronteiras, de crescente e desimpedida circulação ${ }^{4}$, experimenta não apenas o reforço, mas também a multiplicação de fronteiras como dispositivos restritivos da mobilidade.

A preocupação em deter a passagem de suspeitos de terrorismo, de contestados políticos e dos que passam a vir representar ônus aos serviços de seguridade social acarreta um enrijecimento dos dispositivos e práticas de intervenção sobre as fronteiras. Ao mesmo tempo, as exigências de uma economia globalizada demandam uma facilitação tanto dos fluxos de mercadorias e capitais quanto daqueles sujeitos que os personificam, na qualidade de empresários, investidores e trabalhadores expatriados (PÓVOA NETO, 2017, p. 59).

O atravessamento de fronteiras de maneira segura e relativamente simples está restrito a um número bastante reduzido de pessoas. Como os fatores que impulsionam a migração mantêm-se e em muitos casos aumentam, é crescente o contingente daqueles que se arriscam em travessias de maneira indocumentada, insegura, onerosa e, às vezes, fatal. Além dos riscos, mesmo aqueles que conseguem ingressar em um novo território, seja do Estado-nação ou outro, permanecem sob a vigilância constante da sociedade de destino e enfrentam dificuldades na permanência e inserção social. Para esses, "o ingresso de forma não autorizada pode ser considerada pelo Estado uma violação de soberania nacional e ensejar atitudes repressivas tanto de expulsão quanto de detenção" (PÓVOA NETO, 2017, p. 61).

Pautando-se no exercício da soberania do Estado-nação, os deslocamentos populacionais, voluntários ou forçados, frequentemente são alvos de políticas de securitização e muitas vezes associados ao crime. Tais políticas não estão restritas aos aparelhos repressivos do Estado, mas espalham-se em vários dispositivos, práticas e discursos. Não se trata apenas de conter a mobilidade das pessoas, mas de governá-la, inclusive sobre seu movimento no interior dos territórios. Tal governamentalidade produz conhecimentos sobre migrantes e refugiados, tornando-

\footnotetext{
${ }^{4}$ Em consonância com o argumento do "fim das distâncias".
} 
os visíveis, quase sempre como ameaça à ordem e segurança, já que provocam desestabilizações.

\begin{abstract}
Inevitavelmente, os migrantes e refugiados afetam os Estados pelas desestabilizações que eles provocam. Desestabilizar significa provocar a fragilidade de pilares básicos dos Estados, tais como "fronteira", "nacional" e "cidadania". Significa também colocar em xeque a condição material que é exercida desigualmente pelos sujeitos que ocupam o mesmo espaço. Desestabilizar significa, afinal, dialogar com relações de poder. Ocorre, porém, que a racionalidade governamental tende a atribuir um sentido negativo a essas desestabilizações (WALDELY et al, 2015, p. 239).
\end{abstract}

Frequentemente, migrantes e refugiados, antes e depois de adentrarem em um novo território, são associados a violadores da lei, invasores, sendo, portanto, alvos de criminalização. Por outro lado, um seleto grupo de pessoas, geralmente no papel de investidores e turistas, encontram facilidades e estímulos à mobilidade. Em geral, a criminalização das migrações está associada a critérios de diferenciação, classificação e hierarquização entre os que podem e os que não podem entrar e circular.

Nas ações do Estado, no discurso midiático e seus reflexos no senso comum, a migração de certos grupos representa invasão e ameaça. Como resposta, assistese ao surgimento de barreiras físicas, como mostra a figura 1, e jurídicas que buscam afastar o estrangeiro e desestimular futuras migrações. Entretanto, de acordo com Póvoa Neto (2017), os novos muros poderiam sugerir não o fortalecimento da soberania e sim uma projeção espetacularizada disso, mas com eficácia duvidosa.

Figura 1: Muro em Tijuana, na fronteira entre México e Estados Unidos 


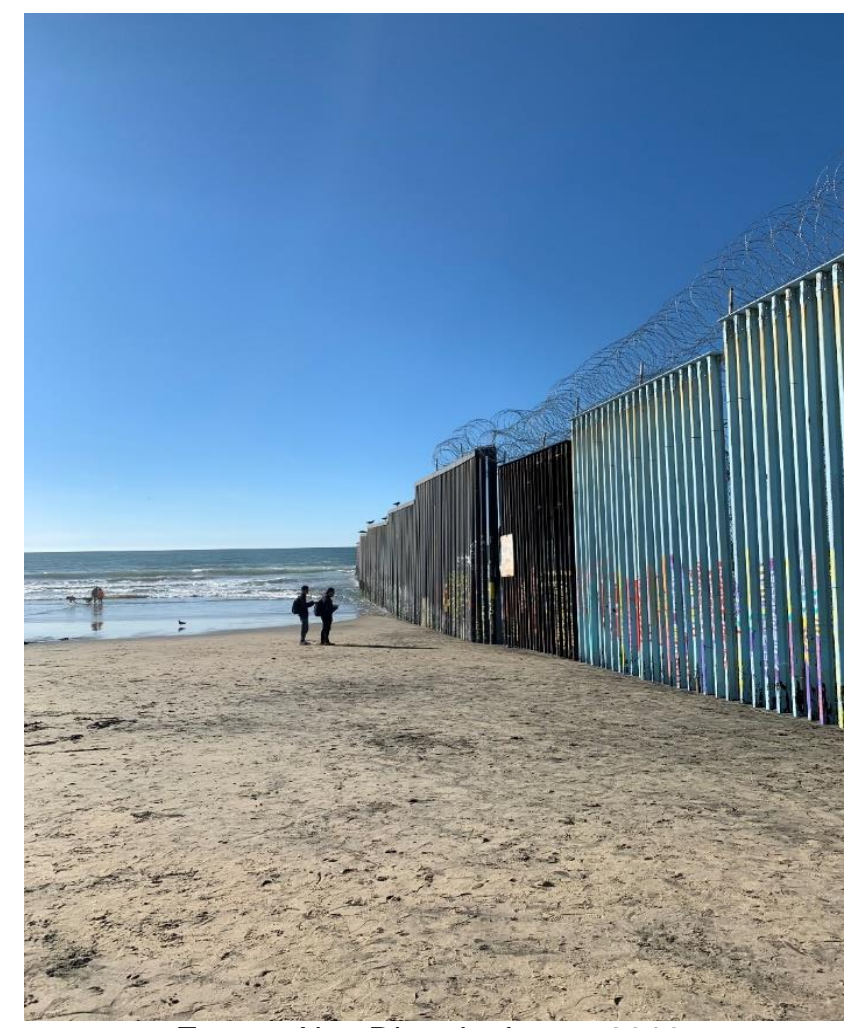

Fonte: Alex Dias de Jesus, 2018.

Acrescenta-se que grande parte dos deslocamentos de população hoje é feita por via aérea, o que torna os aeroportos espaços privilegiados para a execução de medidas de controle e restrição. Os aeroportos, também fronteiras, recebem cada vez mais equipamentos de segurança e sofisticados meios de identificação, classificação e hierarquização de pessoas.

O uso do passaporte, intensificado em períodos de guerra na Europa, passou a ser o principal meio de identificação das pessoas. Seu uso, entretanto, não está livre da seletividade das políticas migratórias. A título de exemplo, o site passport index apresenta um ranking de aceitação desse documento no mundo, considerando a necessidade ou não de visto para entrada nos países, estando a liderança ocupada pelos Emirados Árabes Unidos e a última posição pelo Afeganistão, em 2020.

\section{Políticas migratórias e seus reflexos na migração haitiana}

Configurando-se como um dos principais destinos da migração haitiana há mais de um século, a República Dominicana mantém uma hostilidade crescente em relação aos seus vizinhos. Os haitianos ocupam os trabalhos mais precários, têm as piores remunerações e enfrentam variadas formas de violência e racismo 
institucional. Apesar disso, em 2017, a estimativa era de que quase 500.000 haitianos e descendentes residiam no país (COTINGUIBA, 2019). Os 275 quilômetros de fronteira entre os dois países e a rede de estradas que os conectam apresentam menos obstáculos à entrada do que em outros vizinhos do Caribe, por exemplo.

Às dificuldades de inserção laboral e educacional, ao racismo e às diversas violações de direitos vivenciados pelos haitianos e descentes desde o início do século $X X$, somam-se, atualmente, decisões no campo jurídico que impactam diretamente na vida de um grande número de filhos de haitianos nascidos na República Dominicana. Em 2004, a Ley General de Inmigración institucionalizou uma medida que, na prática, já vinha ocorrendo em alguns cartórios de registro civil desde os anos 1990: a recusa em registrar filhos de haitianos que se encontravam em situação indocumentada.

Até aquele momento, a lei dominicana deixava de conceder a nacionalidade a crianças filhas de diplomatas ou de pessoas "em trânsito" - definidas como aquelas que permaneciam no país por menos de 10 dias. Ou seja, essas situações configuravam-se como exceções à aplicação do princípio jus solis. Com a nova lei de 2004, trabalhadores estrangeiros temporários e migrantes não documentados passaram a ser considerados pessoas "em trânsito", impedindo que muitos filhos de migrantes haitianos adquirissem a nacionalidade dominicana.

A partir de 2007, a Junta Central Eleitoral, órgão responsável pelo registro civil, passou a aplicar a definição de "estrangeiros em trânsito" de forma retroativa, impedindo a renovação e emissão de documentos a dominicanos de ascendência haitiana nascidos antes da lei de 2004 (BERNANDES, 2016). Na continuidade das políticas migratórias restritivas e das práticas discriminatórias, uma nova Constituição dominicana, promulgada em 2010, passou a negar a nacionalidade também a filhos de imigrantes em situação irregular no país.

Art. 18. Nacionalidade. São dominicanos e dominicanas [...] 3. As pessoas nascidas em território nacional, com exceção dos filhos e filhas de estrangeiros membros de legações diplomáticas e consulares, de estrangeiros que estejam em trânsito ou residam ilegalmente em território dominicano [...] (REPÚPLICA DOMINICANA, 2010, p. 5, tradução nossa).

Em setembro de 2013, o Tribunal Constitucional da República Dominicana emitiu a sentença 168-13 que causaria ainda maior impacto na vida dos haitianos e dominicanos de ascendência haitiana residentes no país. A decisão passou a considerar que todos os nascimentos de filhos de imigrantes em situação irregular 
no país, desde 21 de junho de $1929^{5}$, se enquadrariam na definição de pessoas em "trânsito".

Diante disso, todos aqueles que não conseguiram comprovar a situação migratória regular de seus pais a partir de 1929 tornaram-se indocumentados, independente do fato de terem nascido sob a vigência de uma Constituição que Ihes garantia o direito à nacionalidade. Como consequência, uma grande quantidade de dominicanos encontra-se como apátridas e sem documentos regulares, o que os impede de realizar transações bancárias, inserção no mercado de trabalho formal, acesso aos serviços públicos, além do risco de deportação.

Diante de tantos abusos, inclusive respaldados em lei, não é difícil imaginar o porquê de muitos haitianos não terem a República Dominicana como destino permanente, e sim, como uma etapa provisória em seus projetos migratórios. De acordo com Martínez (2011), os haitianos consideram o país vizinho como o menos desejado dos destinos internacionais da migração e a maioria não deseja instalar-se nele, ao menos que saiam de casa pela primeira vez.

Nos Estados Unidos, as maiores restrições à migração a partir do 11 de setembro de 2001 e a crescente militarização da fronteira com o México também afetaram a migração haitiana. Tais medidas obrigaram muitos haitianos a redefinirem seus projetos migratórios e redirecionarem os fluxos dessa migração, acrescentando novos destinos. Nesse contexto, países da América do Sul como Chile e Brasil passaram a ser incorporados ao espaço transnacional haitiano, mas o desejo de migrar para os Estados Unidos, onde vive uma expressiva quantidade dos haitianos no exterior, permanece em grande parte dos migrantes.

Recentemente, seguindo um intenso deslocamento e atravessamento de fronteiras pelo continente americano, entre 2016 e 2017, milhares de haitianos chegaram a Tijuana, no estado mexicano da Baixa Califórnia, com a esperança de entrarem nos Estados Unidos, beneficiados por pedidos de reunificação familiar ou refúgio. Entretanto, em setembro de 2016, o governo Barack Obama restringiu as entradas, ampliando o número de prisões e deportações de indocumentados (GARBEY-BUREY, 2017). Adicionalmente, em 20 de novembro de 2017, o Governo de Donald Trump decidiu pôr fim ao Status de Proteção Temporal [Temporary

\footnotetext{
${ }^{5}$ Data da Constituição Dominicana de 1929, na qual filhos de estrangeiros em trânsito não mais teriam direito à nacionalidade dominicana.
} 
Protected Status] TPS 6 para os haitianos, dando um prazo de dezoito meses para que mais de 58.000 beneficiários voltassem ao Haiti ou buscassem outra alternativa de permanência. Mais uma vez, em mais uma nova etapa, as fronteiras se fecharam, exigindo novas estratégias de atravessamento ou contornamento das barreiras. Afinal, essa migração "trata-se de um deslocamento intenso e simultâneo para distintos países da região, muitas vezes recorrendo a trajetos que se convertem em uma acumulação de rechaços nas distintas fronteiras recorridas" (STEFONI, 2017, p. 8, tradução nossa).

Nas Bahamas, onde a migração haitiana teve início nos anos 1950, grande parte dos migrantes de diversos países do Caribe ingressam no arquipélago com o objetivo de acessarem os Estados Unidos através da Flórida (ver figura 2). Mesmo assim, a permanência no país pode durar anos ou mesmo a vida inteira. "Isto marca a migração haitiana nestas ilhas com um selo particular de não pertencimento" (ALFONSO, 2012, p. 23, tradução nossa).

${ }^{6}$ O TPS é um programa migratório, criado em 1990 pelo governo dos Estados Unidos, que concede permissão extraordinária para entrada e permanência de pessoas de outros países afetados por conflitos armados e desastres naturais. 
Figura 2- Mapa de distancias entre o Haiti e alguns destinos da migração haitiana

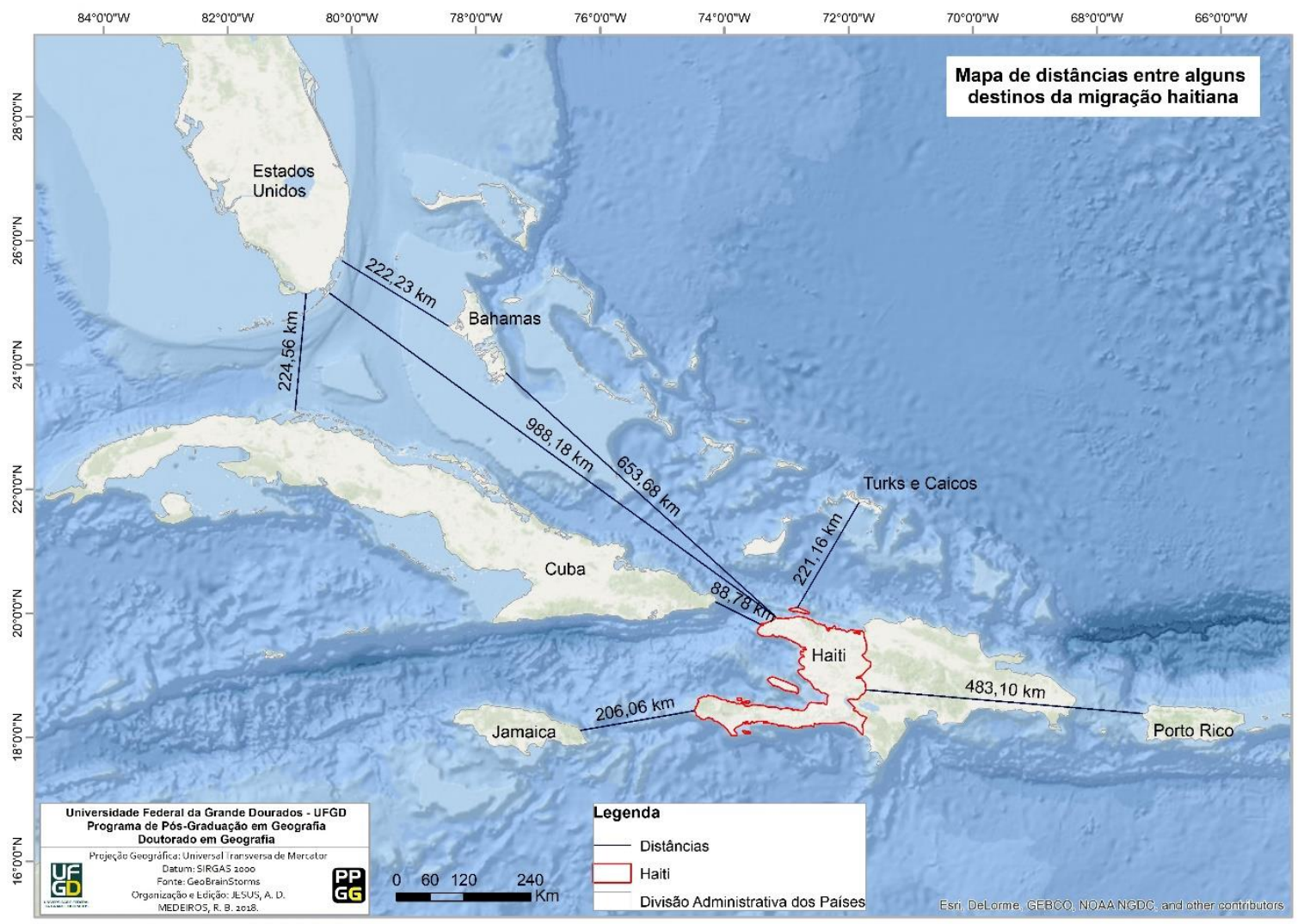

Fonte: Alex Dias de Jesus, 2018.

No novo contexto migratório que se iniciou após o terremoto que atingiu o Haiti em janeiro de 2010, o debate em torno na migração haitiana nas Bahamas voltou a se acirrar. A nova política migratória das Bahamas, em vigor desde 1 de novembro de 2014, exige que todos tenham um passaporte ou documento bahamês. Sem passaporte ou autorização de trabalho, imigrantes são sumariamente detidos e, em alguns casos, deportados. Embora essa lei sirva para os imigrantes em geral, é principalmente sobre os haitianos que seu peso recai, pois são os mais excluídos da restrita política de regularização. Nos últimos anos, aumentaram as abordagens policiais e detenções nas favelas de Nassau, capital do país, onde vive a maioria dos haitianos (ROBLES, 2015).

$\mathrm{Na}$ busca de alternativas diante do agravamento da crise humanitária no Haiti após o terremoto de 2010, milhares de haitianos passaram a migrar para países da América do Sul, especialmente para o Brasil e posteriormente para o Chile. Valendose da isenção de visto para turista no Equador ${ }^{7}$, os haitianos passaram a ingressar

\footnotetext{
${ }^{7}$ Baseado no princípio da cidadania universal disposto na Constituição do Equador, promulgada em 2008, em junho do mesmo ano o presidente Rafael Correa publicou um Decreto Executivo que eliminou a necessidade de vistos de turistas para todas as nacionalidades do mundo. Menos de um ano depois, algumas exceções foram implementadas para alguns países asiáticos.
} 
nesse país por via aérea e seguir diferentes rotas pelo Peru, por via terrestre, até chegarem ao Brasil. O Peru passou a exigir visto de turismo para os haitianos a partir de 2012, o que provocou o surgimento de redes de tráfico de pessoas, expondo-os ainda mais às extorsões e abusos (NIETO, 2014).

\begin{abstract}
A crise estrutural e humanitária no Haiti, e o contexto global de assimetria econômica e mundialização das migrações, entre outros processos, posicionou Brasil e Chile como destinos de referência para a população haitiana. Por sua parte, países como Equador e Peru constituem destinos de chegada e trânsito, respectivamente. De todo modo, pequenas comunidades haitianas têm se estabelecido em ambos os países. As comunidades haitianas maiores na América do Sul assentaram-se no Brasil e Chile, com uma maior chegada nos últimos dois anos para este último, produto da crise socioeconômica da principal potência do subcontinente (PEDEMONTE et al, 2017, p. 10) [Tradução nossa].
\end{abstract}

No Brasil, país que registrou mais de 110.000 entradas de haitianos entre 2010 e 2018, de acordo com os registros administrativos da Polícia Federal (SISMIGRA, 2010-2018), a migração teve início antes da entrada em vigor de alguma política migratória específica. Diante do crescente número de entradas pelas fronteiras internacionais da região norte do país durante os anos de 2010 e 2011, o Conselho Nacional de Imigração (CNIg) publicou a resolução no 97/2012 concedendo o visto humanitário para haitianos, mas limitando-se a 1.200 por ano.

Além da emissão limitada de vistos, o Brasil passou a reforçar o controle nas fronteiras, impedindo a entrada dos indocumentados. Em consequência, em três momentos entre os anos de 2012 e 2013, o governo brasileiro autorizou o fechamento da fronteira e centenas de haitianos permaneceram na cidade peruana de Iñapari à espera da permissão de entrada ou na cidade brasileira de Tabatinga, aguardando autorização para seguir viagem pelo Brasil.

Essa medida mostrou-se insuficiente diante do crescente número de pedidos feitos na Embaixada brasileira em Porto Príncipe, no Haiti. Além disso, como o visto poderia ser emitido apenas no Haiti, excluiu um grande número de haitianos que já estavam em deslocamento por outros países ou residiam em outros destinos. Com a chegada de cada vez mais migrantes indocumentados no Brasil, o CNIg publicou a resolução 102/2013, extinguindo o limite de vistos e concedendo a autorização de entrada também a partir de outras embaixadas brasileiras.

Atualmente, a regulamentação da migração haitiana para o Brasil ainda se dá por meio do visto humanitário. Entretanto, este passou a ser normatizado pela Portaria Interministerial no 10, de 6 de abril de 2018, substituída recentemente pela Portaria Interministerial $n \div$ 12, de 20 de dezembro de 2019. No rol de retrocessos 
sofridos pelo golpe parlamentar de 2016, o governo brasileiro voltou a implementar restrições à mobilidade haitiana. De acordo com o novo instrumento, apenas residentes no Haiti poderão solicitar acolhida humanitária e o visto é emitido exclusivamente na Embaixada brasileira de Porto Príncipe.

No Chile, as mudanças na política migratória do governo de Sebastián Piñera também impactaram diretamente na migração haitiana. A partir de abril de 2018, o país passou a exigir vistos de turistas para os haitianos, com permanência máxima de 90 dias. Passou também a emitir vistos humanitários de reunião familiar apenas a cônjuges, filhos menores de idade ou filhos estudantes até 24 anos, com um limite máximo anual de 10 mil vistos (CHILE, 2018). Essas mudanças, além do racismo e xenofobia crescentes e a concorrência com a mão de obra dos venezuelanos, impulsionaram a saída de haitianos do Chile em direção ao Brasil.

Depois de um longo trajeto pela Bolívia, os haitianos entram no Brasil através da cidade de Corumbá, no Mato Grosso do Sul (ver figura 3). Como geralmente não portam o visto de turista exigido pela Bolívia, sofrem ameaças de deportações, extorsões, roubos frequentes e violências diversas. Segundo informações da Polícia Federal $^{8}$, cerca de 1.200 haitianos chegaram ao Mato Grosso do Sul nos sete primeiros meses de 2018. Com objetivo de encontrar familiares e amigos em diversos estados brasileiros, em destaque para os da região sul, esses migrantes acionam suas redes sociais e põem em prática mais uma etapa do seu projeto migratório.

\footnotetext{
${ }^{8}$ Em audiência pública realizada na cidade de Corumbá em 3 de agosto de 2018.
} 


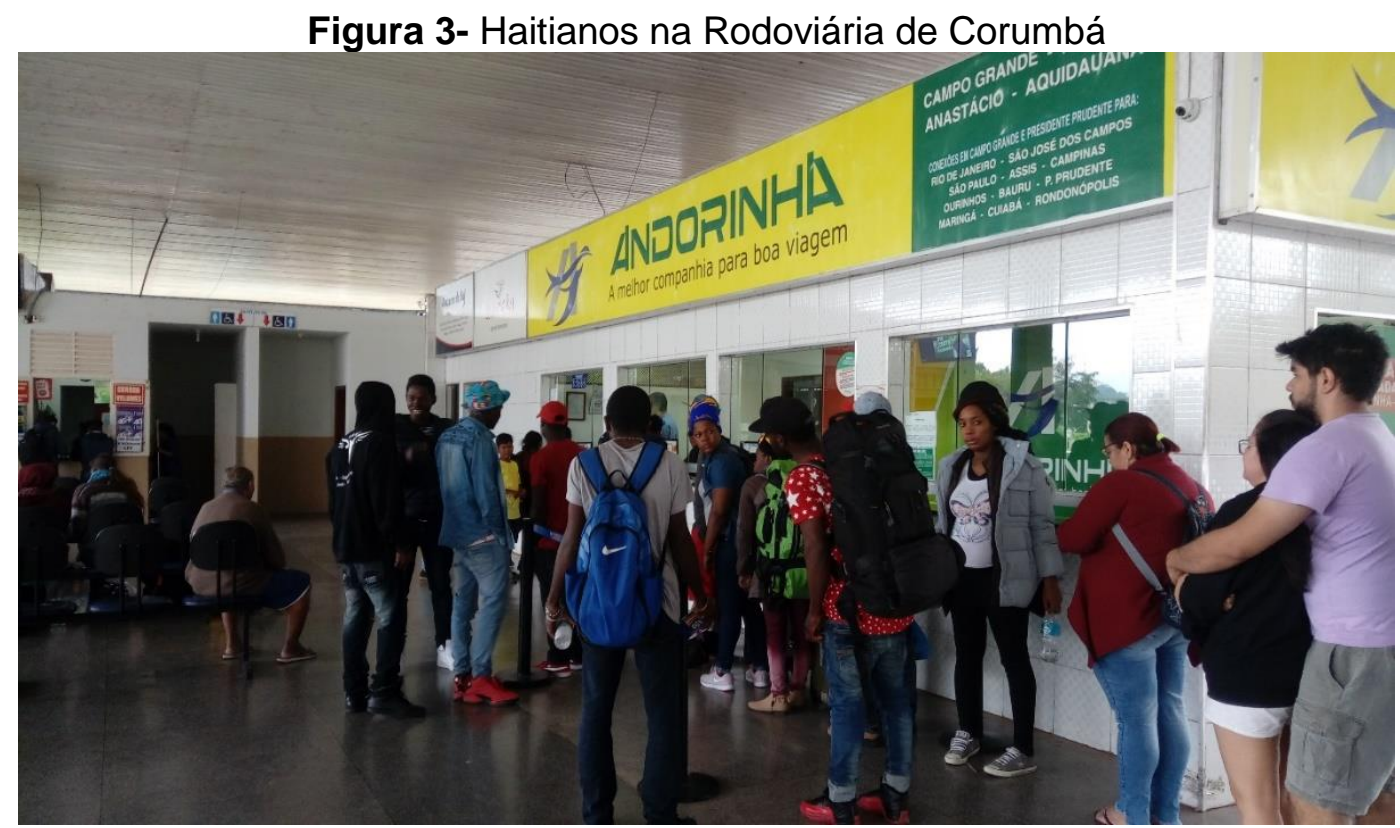

Fonte: Alex Dias de Jesus, 2018.

Durante o ano de 2019, além da continuidade da migração de haitianos do Chile para o Brasil, o município de Bonfim, em Roraima, registou a entrada de mais de 13.000 haitianos vindos da Guiana ${ }^{9}$. Beneficiados pela isenção de vistos de turistas, muitos haitianos desembarcam de avião na capital Georgetown e seguem em vans para a cidade de Lethem, na fronteira com o Brasil, e depois para as cidades de Boa Vista e Manaus. Assim como ocorre em Corumbá, essas cidades são locais de passagem para a maioria que se dispersa para uma variedade cada vez maior de municípios brasileiros. Enquanto Corumbá é uma porta de entrada daqueles que estão abandonando o Chile, Bonfim é uma porta de entrada daqueles que vêm diretamente do Haiti.

Ao chegarem ao Brasil também não encontram facilidades, tendo em vista a exigência do visto humanitário que voltou a ser concedido exclusivamente no Haiti. Assim, recebem uma notificação de que devem regularizar a situação migratória em 60 dias, com o risco de serem deportados caso não o façam. Mais uma vez, as fronteiras se fecham diante desse intenso e constante fluxo migratório e exige dos haitianos novas estratégias de mobilidade para cruzar ou contornar as barreiras físicas e/ou jurídicas.

A recente migração de haitianos em vários países do continente americano, produto de uma crise humanitária que não mostra sinais de término, tem se mostrado bastante vinculada às políticas migratórias e com o "giro securitário", como

\footnotetext{
9 Nova onda de haitianos chega ao Brasil pela Guiana e engrossa êxodo de estrangeiros em Roraima. Disponível em: https://g1.globo.com/rr/roraima/noticia/2019/12/16/nova-onda-de-haitianoschega-aobrasil-pela-guiana-e-engrossa-exodo-de-estrangeiros-em-roraima.ghtml.
} 
propõe Huerta (2015), que envolve a mobilidade internacional de pessoas. O erguimento de barreiras que dificultam ou impedem o acesso dos haitianos em vários destinos contribui para o redirecionamento de fluxos desses migrantes, alterando também o espaço social transnacional do Haiti, na medida em que novos polos são incorporados a essa mobilidade.

\section{Considerações Finais}

Nas páginas anteriores, apontamos que configuração atual da migração haitiana está profundamente marcada pela dinâmica das fronteiras em diversos países. As políticas migratórias mais restritivas na América do Norte, principalmente após o 11 de setembro de 2001, bem como na Europa, alteraram as direções desses fluxos, fazendo com que novos destinos fossem incorporados. Embora essa migração esteja prioritariamente orientada para países do Hemisfério Norte, o fechamento dessas fronteiras impulsionou fluxos em outras direções, a exemplo de países da América do Sul.

Em outros países, historicamente vinculados com a migração haitiana, alterações na política migratória refletiram nas condições de vida desses migrantes, aumentando o grau de indocumentação e vulnerabilidade. Os casos da República Dominicana e Bahamas são emblemáticos, já que as mudanças nos dispositivos legais afetam quase exclusivamente os haitianos. Em ambos os países, o racismo institucional e o poder discricionário exercido pelas polícias ameaçam a permanência dos migrantes.

Por outro lado, iniciativas no campo das políticas migratórias em países da América do Sul, a exemplo do Decreto Executivo do presidente Rafael Corrêa, do Equador, que aboliu a necessidade de visto de turista para qualquer nacionalidade, em 20 de junho de 2008, permitindo ingressar e permanecer no país por até noventa dias e as resoluções 97/2012 e 102/2013 do Conselho Nacional de Imigração do Brasil que concedeu e regulamentou a concessão de visto humanitário para os haitianos são exemplos de políticas migratórias que contribuíram acrescentando novas possibilidades para essa migração.

Demonstramos também que, inclusive nos novos destinos da migração haitiana no século XXI, como Brasil e Chile, restrições à mobilidade foram postas em prática. No primeiro, o processo de concessão de vistos de residência voltou a ser concedido exclusivamente na Embaixada brasileira no Haiti, o que inviabilizou a aquisição do documento pelos migrantes que residem em outros países ou que se 
encontram em trânsito, favorecendo o surgimento de redes de agenciamento ${ }^{10}$ que lucram com a indocumentação. No segundo, as mudanças com o Decreto presidencial de abril de 2018 impediram que os haitianos que entraram com vistos de turistas os transformassem em vistos de trabalho e definiu que estes devem ser obtidos também no Haiti.

Apesar de algumas iniciativas no âmbito das políticas migratórias que foram implementadas sob o discurso da ajuda humanitária a partir do agravamento da situação de crise com o terremoto de 2010, elas ficaram restritas à concessão do visto humanitário ou à possibilidade de entrada sem ele. Na maioria dos casos, os planos para a regularização da migração indocumentada impõem exigências difíceis de serem conseguidas no contexto de uma migração precarizada, como a comprovação de exercício de atividade laboral.

Mais numerosos do que as possibilidades de abertura e acolhimento são os rechaços e o erguimento de barreiras, exigindo dos haitianos sempre um novo atravessamento. Prova disso, foi a arriscada mobilidade de haitianos que saíram do Brasil e do Chile durante os anos de 2016 e 2017 tentando ingressar nos Estados Unidos e, diante das restrições do governo de Barack Obama e posteriormente do Governo de Donald Trump, foram obrigados a permanecer nas cidades fronteiriças no norte do México.

\section{REFERÊNCIAS}

ALFONSO, Haroldo Dilla. La migración haitiana en el Caribe: una proposta para la acción. Servicio Jesuita de Migrantes. Santo Domingo, 2012.

BERNARDES, Pedro Henrique Dias Alves. A apatridia dentro do regime interamericano de direitos humanos: o caso de dominicanos de ascendência haitiana. Anais do II Simpósio Internacional Pensar e Repensar a América Latina. São Paulo, 2016. p. 1-14.

BRASIL. Portaria Interministerial no 10, de 6 de abril de 2018. Dispõe sobre a concessão do visto temporário e da autorização de residência para fins de acolhida humanitária para cidadãos haitianos e apátridas residentes na República do Haiti. Disponível em: https://sistemas.mre.gov.br/kitweb/datafiles/Cingapura/enus/file/Portaria\%2010-2018.pdf Acesso feito em 1 de agosto de 2018.

BRASIL. Portaria Interministerial no 12, de 20 de dezembro de 2019. Dispõe sobre a concessão de visto temporário e de autorização de residência para fins de acolhida humanitária para cidadãos haitianos e apátridas residentes na República do Haiti.

CHILE. Nueva Ley de Migraciones. Disponível em:

https://www.gob.cl/nuevaleydemigracion/ Acesso feito em 23 de agosto de 2018.

10 Referimo-nos aos serviços envolvidos na viabilização da migração como transporte, hospedagem, propinas e, em alguns casos, falsificação de documentos. 
CNIG - Conselho Nacional de Imigração. Resolução Normativa n. 97, de 12 de janeiro de 2012. Dispõe sobre a concessão de visto permanente previsto no art. 16 da Lei n. 6.815, de 19 de agosto de 1980, a nacionais do Haiti. Brasília, 2012.

CNIG - Conselho Nacional de Imigração. Resolução Normativa nº. 102, de 26 de abril de 2013. Altera a Resolução Normativa № 97 de 12 de janeiro de 2012. Brasília, 2013.

COTINGUIBA, Geraldo Castro. Aletranje: a pertinência da família na ampliação do espaço social transnacional haitiano - o Brasil como uma nova baz. Tese (Doutorado em Desenvolvimento Regional e Meio Ambiente). UNIR, 2019.

DORFMAN, Adriana. A condição fronteiriça diante da securitização das fronteiras do Brasil. In: NASCIMENTO, Durbens Martins e PORTO, Jadson Luis Rebelo. (Orgs.). Fronteiras em perspectiva comparada e temas de defesa da Amazônia. Belém: EDUFPA, 2013. p. 97124.

FARIA, Maria Rita Fontes. Migrações internacionais no plano multilateral: reflexões para a política externa brasileira. Brasília: FUNAG, 2015.

GARBEY-BUREY, Rosa María. Estrategias migratorias en el tránsito de emigrantes haitianos hacia Estados Unidos. Huellas de la Migración, Vol. 2 N. 4, 2017. p. 93-123.

GLICK-SCHILLER, Nina. Locality, Globality and the Popularization of a Diasporic Consciousness: Learning from the Haitian Case. In: JACKSON, Regine O. Geographies of the Haitian Diaspora. New York: Routledge, 2011. p. xxi-xxix.

HANDERSON, Joseph. Diaspora. As dinâmicas da mobilidade haitiana no Brasil, no Suriname e na Guiana Francesa. 2015. Tese (Doutorado em Antropologia Social), UFRJ/Museu Nacional. Rio de Janeiro.

HUERTA, Amarela Varela. La "securitización" de la gubernamentalidad migratoria mediante la "externalización" de las fronteras estadounidenses a Mesoamérica. Con-temporánea. V. 2, n. 4. 2015. p. 5-19.

MARTÍNEZ, Samuel. The onion of oppression: haitians in the Dominican Republic. In: JACKSON, Regine O. Geographies of the Haitian Diaspora. New York: Routledge, 2011. p. 51-70.

NIETO, Carlos. Migración haitiana a Brasil: redes migratorias y espacio social transnacional. $1^{\underline{a}}$ ed. Buenos Aires: CLACSO, 2014.

OLIVEIRA, Tito Carlos Machado de. Tipologias das relações fronteiriças: elementos para o debate teórico-práticos. In: OLIVEIRA, Tito Carlos Machado de. (Org.). Territórios sem limites: estudos sobre fronteiras. Campo Grande: Ed. UFMS, 2005. p. 377-408.

ORGANIZAÇÃO INTERNACIONAL PARA AS MIGRAÇÕES - OIM. Informe sobre las migraciones en el mundo 2020. Genebra: Organização Internacional para as Migrações, 2019.

PASSPORTINDEX. Disponível em:

https://www.passportindex.org/comparebyPassport.php?p1=af\&fl=\&s=yes Acesso feito em 22 de abril de 2020.

PEDEMONTE, Nicolás Rojas et al. Introducción. In: PEDEMONTE, Nicolás Rojas e KOECHLIN, José. (eds.). Migración Haitiana Hacia Sur Andino. Santiago: SJM, 2017. p. 9-13. 
PIÑEIRO, Rodolfo Cruz e LANDA, Nancy. El muro fronterizo de Trump y la política migratoria estadounidense. In: BAENINGER, Rosana et al (Orgs.). Migrações fronteiriças. Campinas: Núcleo de Estudos de População "Elza Berquó”, 2018. p. 15-29.

PÓVOA NETO, Helion. Migrações e fronteiras. In: SUERTEGARAY, Dirce Maria et al (Orgs.). Geografia e conjuntura brasileira. Rio de Janeiro: Consequência, 2017. p. 59-73.

RAFFESTIN, Claude. A ordem e a desordem ou os paradoxos da fronteira. In: OLIVEIRA, Tito Carlos Machado de. (Org.). Territórios sem limites: estudos sobre fronteiras. Campo Grande: Ed. UFMS, 2005. p. 9-15.

REPÚBLICA DOMINICANA. Constituición Política de la República Dominicana, 2010. Disponível em:

file:///D:/Meus\%20Documentos/Downloads/Constituci\%C3\%B3n\%20Dominicana\%202015.p df Acesso feito em 05 de setembro de 2018.

ROBLES, Frances. Onde os haitianos não são bem vindos. Gazeta do Povo, 2015. Disponível em: http://www.gazetadopovo.com.br/mundo/onde-os-haitianos-nao-sao-bemvindos-ejra6dvxckun9vb2osiw8d1zi Acesso feito em 07/10/2017.

SISMIGRA - Sistema de Registro Nacional Migratório. Microdados 2010-2018. Disponível em: https://portaldeimigracao.mi.gov.br/pt/dados/microdados/1733-

obmigra/dados/microdados/401205-sismigra. Acesso feito em: 22 de abril de 2020.

STEFONI, Carolina. Prólogo. In: PEDEMONTE, Nicolás Rojas e KOECHLIN, José. (eds.). Migración Haitiana Hacia Sur Andino. Santiago: SJM, 2017. p. 7-8.

WALDELY, Aryadne Bittencourt et al. "Migração como crime, êxodo como liberdade".

Revista Interdisciplinar da Mobilidade Humana, n. 45, p. 235-247, jul./dez. 2015.

\title{
NOTAS DE AUTOR
}

\section{CONTRIBUIÇÃO DE AUTORIA}

\begin{abstract}
Alex Dias de Jesus - Concepção. Coleta de dados, Análise de dados, Elaboração do manuscrito, revisão e aprovação da versão final do trabalho.

Jones Dari Goettert - Participação ativa da discussão dos resultados, Elaboração do manuscrito, revisão e aprovação da versão final do trabalho.
\end{abstract}

\section{FINANCIAMENTO}

Não se aplica.

\section{CONSENTIMENTO DE USO DE IMAGEM}

Não se aplica.

\section{APROVAÇÃO DE COMITÊ DE ÉTICA EM PESQUISA}

Não se aplica.

CONFLITO DE INTERESSES

Não se aplica.

\section{LICENÇA DE USO}

Este artigo está licenciado sob a Licença Creative Commons CC-BY. Com essa licença você pode compartilhar, adaptar, criar para qualquer fim, desde que atribua a autoria da obra.

\section{HISTÓRICO}

Recebido em: 12-10-2019

Aprovado em: 28-04-2020 